\title{
Minimização da produção de lodo no tratamento de águas de abastecimento mediante uso do cloreto de polialumínio e sua disposição em estações de tratamento de esgotos
}

\section{Minimization of water treatment plant sludge production with polyaluminium chloride application and its disposal in wastewater treatment plants}

\author{
Sidney Seckler Ferreira Filho \\ Engenheiro Civil pela Escola Politécnica da Universidade de São Paulo (EPUSP). Professor-associado do Departamento \\ de Engenharia Hidráulica e Sanitária da EPUSP \\ Bárbara Elisabeth Waelkens \\ Engenheira Ambiental pela Epusp. Pós-Graduanda do Departamento de Engenharia Hidráulica e Sanitária da EPUSP
}

\begin{abstract}
Resumo
Uma das possibilidades para a redução da produção de lodo em estações de tratamento de água (ETAs) é o uso do cloreto de polialumínio (CPA) como coagulante, que pode ser aplicado de forma isolada ou em conjunto com sais de ferro. Este trabalho objetivou estudar o uso do CPA no que diz respeito à produção de lodo, bem como avaliar o impacto do lançamento de lodos de ETAs em estações de tratamento de esgoto (ETEs) do tipo lodos ativados convencional. Observou-se que a produção de lodo do CPA apresentou valores próximos em comparação ao sulfato de alumínio, em torno de 4,75 mg de massa seca para cada $1 \mathrm{mg}$ de Al, e o seu eventual lançamento para posterior processamento em ETEs deverá alterar a qualidade físico-química do lodo desidratado, sendo esta função do tipo e dosagem de coagulante e suas impurezas.
\end{abstract}

Palavras-chave: produção de lodo; tratamento de água; coagulação; cloreto de polialumínio; tratamento de esgotos

\begin{abstract}
One possible strategy to reduce sludge production in water treatment plant (WTP) is the application of polyaluminium chloride (PAC) as the sole coagulant or together with iron salts. The purpose of this paper was to investigate PAC usage with regard to sludge production as well as to evaluate impacts of discharging WTP sludge in activated sludge wastewater treatment plants (WWTPs). It was observed that PAC-based sludge production presented values close to aluminum sulfate-based sludge production, which was around $4.75 \mathrm{mg}$ of dry solids per mg of Al. Furthermore, eventual discharge of PAC-based sludge in a WWTP should change the physical and chemical quality of the dry sludge, which is a function of coagulant type, coagulant dosage and of the impurities present in the coagulant's formulation.
\end{abstract}

Keywords: sludge production; water treatment; coagulation; polyaluminium chloride; wastewater treatment.

\section{Introdução}

Tradicionalmente, o tratamento convencional de águas de abastecimento tem empregado sais de alumínio e ferro como coagulantes, sendo que os mais comumente disponíveis no mercado são o sulfato de alumínio, sulfato férrico e cloreto férrico. Uma das maiores preocupações existentes com respeito à operação de estações de tratamento de água (ETAs) tem sido a necessidade de compatibilização da melhoria do processo de coagulação e a minimização da formação de resíduos oriundos da precipitação de sais metálicos na forma de hidróxidos de alumínio ou ferro. De acordo com Januário e Ferreira Filho (2007), os custos de transporte e disposição final de lodos

Endereço para correspondência: Escola Politécnica da Universidade de São Paulo - Departamento de Engenharia Hidráulica e Sanitária - Avenida Professor Almeida Prado, Travessa 2, 271 - Cidade Universitária - 05508-900 - São Paulo (SP), Brasil - Tel.: (11) 3091-5220 - E-mail: ssffilho@usp.br

Recebido: 4/6/08 - Aceito: 3/10/08 - Reg. ABES: 089/08 
de ETAs em regiões metropolitanas tem se situado em torno de R\$ 100,00 a 150,00 por tonelada, o que tem justificado conduções de pesquisas e estudos experimentais que permitam a redução dos custos de tratamento com produtos químicos, bem como com a geração de lodo. Considerando-se a necessidade de que as ETAs existentes ou em fase de concepção tenham que ser dotadas de sistemas de tratamento da fase sólida, quanto maiores forem os esforços no sentido de minimizar a geração de lodo, os custos associados à implantação de seus sistemas de adensamento e desidratação tenderão a ser menores. De acordo com Roth (2008), os custos de implantação de sistemas de tratamento de lodos em estações de tratamento de água podem variar de 30 a $40 \%$ do custo total do sistema de tratamento, o que justifica a investigação de técnicas de tratamento de água que permitam a redução na massa de sólidos gerada no processo de tratamento.

A avaliação da produção de lodo em ETAs pode ser efetuada de modo distinto, sendo que, para ETAs já existentes, a sua determinação pode ser estimada in loco por meio do monitoramento dos seus diversos processos e operações unitárias durante um intervalo de tempo em que sejam contempladas as variações da água bruta e das características do tratamento (tipo e dosagem de coagulante, $\mathrm{pH}$ de coagulação, entre outros).

A obtenção de dados que tenham por propósito permitir o cálculo da produção de lodo para ETAs em fase de projeto é mais difícil, podendo ser estimada por meio de execução de ensaios de tratabilidade ou mediante utilização de equações empíricas. Assumindo-se que o residual de alumínio e ferro é desprezível na água tratada, a produção de lodo para coagulantes a base de alumínio (sulfato de alumínio) e ferro (sulfato férrico e cloreto férrico) pode ser estimada através das seguintes equações (AMERICAN WATER WORKS ASSOCIATION, 1987; AMERICAN SOCIETY OF CIVIL ENGINEERS, 1996):

$$
\begin{aligned}
& P_{L}=Q \cdot\left(4,89 \cdot D_{A l}+S S T+C A P+O A\right) \cdot 10^{-3} \\
& P_{L}=Q \cdot\left(0,805 \cdot D_{F e}+S S T+C A P+O A\right) \cdot 10^{-3}
\end{aligned}
$$

onde:

$\mathrm{P}_{\mathrm{L}}$ : produção de lodo seco em kg/dia $\left(\mathrm{MT}^{-1}\right)$;

$\mathrm{Q}$ : vazão de água bruta em $\mathrm{m}^{3} /$ dia $\left(\mathrm{L}^{3} \mathrm{~T}^{-1}\right)$;

$\mathrm{D}_{\mathrm{Al}}$ : dosagem de sais de alumínio, expresso como $\mathrm{Al} \mathrm{em} \mathrm{mg/L,}$ $\left(\mathrm{ML}^{-3}\right)$

$\mathrm{D}_{\mathrm{Fe}}$ : dosagem de sais de ferro, expresso como sulfato férrico em $\mathrm{mg} / \mathrm{L}$ $\left(\mathrm{ML}^{-3}\right)$;

SST: concentração de sólidos totais em suspensão na água bruta em $\mathrm{mg} / \mathrm{L}\left(\mathrm{ML}^{-3}\right)$;

CAP: concentração de carvão ativado em pó em mg/L $\left(\mathrm{ML}^{-3}\right)$; $\mathrm{AO}$ : outros aditivos em mg/L (sílica ativada, polímeros, etc.) $\left(\mathrm{ML}^{-3}\right)$.

Os coeficientes 4,89 e 0,805 presentes nas Equações 1 e 2 foram obtidos partindo-se do pressuposto de que todo o alumínio ou ferro adicionado na água bruta precipita-se como hidróxido metálico e a cada molécula de $\mathrm{Fe}(\mathrm{OH})_{3}$ ou $\mathrm{Al}(\mathrm{OH})_{3}$ são incorporadas cerca de três a quatro moléculas de água.

Mais recentemente, tem sido pesquisada a aplicação de coagulantes poliméricos orgânicos e inorgânicos em substituição parcial ou total aos coagulantes inorgânicos mais comumente empregados no tratamento convencional de águas de abastecimento (BARBOSA; MENDES; BAYLÃO, 2003; FERREIRA FILHO et al, 2003; DALSASSO; SENS, 2006). Dentre esses, os coagulantes do tipo cloreto de polialumínio (CPA) são os mais comuns e de maior disponibilidade no mercado nacional, sendo que, em face de suas características físico-químicas, a sua aplicação tem possibilitado o seu emprego em ETAs que apresentam limitações operacionais em seus sistemas de pré-alcalinização.

Os coagulantes inorgânicos poliméricos a base de alumínio são produzidos a partir da bauxita, sendo que, durante o seu processo de produção, a solução de Al é parcialmente neutralizada por meio da adição de uma base forte, tipicamente $\mathrm{NaOH}$ (AMERICAN WATER WORKS ASSOCIATION, 1989). Desse modo, quando ocorre a adição de íons $\mathrm{OH}^{-}$na solução de coagulante, as reações de hidrólise da espécie $\mathrm{Al}^{+3}$ vão sendo favorecidas e, dessa forma, a formação das espécies monoméricas e poliméricas passam a ocorrer diretamente na solução de coagulante ao invés de ocorrerem na fase líquida, diferentemente do que ocorre com a aplicação do sulfato de alumínio.

Uma vez que se podem adicionar diferentes concentrações molares de $\mathrm{OH}^{-}$em relação à concentração molar de $\mathrm{Al}^{+3}$, a produção de soluções de CPA podem permitir a fabricação de diferentes tipos de coagulantes que tendem a apresentar distintas características de composição e comportamento no que concerne ao processo de coagulação (PERNITSKI; EDZWALD, 2003).

Em face do comportamento químico distinto dos CPAs em relação ao sulfato de alumínio, uma das maiores dúvidas com respeito ao seu emprego como coagulante no tratamento de águas de abastecimento está associada ao seu potencial de formação de lodo, uma vez que a existência das espécies poliméricas formadas anteriormente à sua adição na fase líquida tenderia a ficar na forma solúvel, possibilitando, dessa forma, a redução da carga das partículas coloidais e reduzindo a formação de espécies insolúveis. A possibilidade de os coagulantes do tipo CPA apresentarem uma menor capacidade de produção de lodo em comparação aos coagulantes tradicionalmente empregados no tratamento de águas de abastecimento tem oferecido uma alternativa para a sua minimização. Ainda que algumas ETAs não possam fazer o uso unicamente do CPA como agente coagulante, a sua aplicação pode ocorrer de forma conjunta com sais de ferro, possibilitando, assim, uma redução global na produção de lodo, sem que haja prejuízo à qualidade da água tratada.

A redução da produção de lodo em ETAs torna-se importante não somente pela minimização dos custos operacionais com produtos químicos, mas também por possibilitar que possam ser encaminhados via rede coletora de esgotos sanitários para fins de 
processamento em ETEs. A maior vantagem dessa alternativa reside no fato de poderem ser concentradas em uma única instalação física todas as unidades de processamento da fase sólida (unidades de adensamento e desidratação), o que reduz consideravelmente os seus custos de operação e manutenção. Atualmente, algumas concessionárias têm optado por essa solução, podendo-se citar a Companhia de Saneamento Básico do Estado de São Paulo (Sabesp) que dispõe o lodo da ETA Rio Grande na ETE ABC, sendo que as estações possuem vazões da ordem de $5,0 \mathrm{~m}^{3} / \mathrm{s}$ e $1,5 \mathrm{~m}^{3} / \mathrm{s}$; da mesma forma, encontra-se em fase de construção um sistema de envio de lodo via rede coletora de esgotos sanitários da ETA Alto da Boa Vista $\left(14 \mathrm{~m}^{3} / \mathrm{s}\right)$ para a ETE Barueri $\left(9,5 \mathrm{~m}^{3} / \mathrm{s}\right)$.

Desse modo, a viabilidade do lançamento de lodos de ETAs na rede coletora de esgotos sanitários e seu processamento em ETEs torna-se dependente da massa de sólidos gerada na ETA e do impacto que pode ocasionar nas operações unitárias que compõem a ETE, sendo uma alternativa que precisa ser avaliada em função da concepção da ETE. Sendo assim, objetivando permitir o lançamento de lodos de ETAs e seu posterior processamento em ETEs, faz-se necessário avaliar a produção de lodo gerado no processo de tratamento de água, bem como estudar alternativas técnicas para a sua minimização e avaliar os impactos oriundos dessa prática na qualidade do lodo final gerado no processo de tratamento de esgotos, particularmente quando se emprega CPA isoladamente ou em conjunto com sais de ferro como agentes coagulantes.

\section{Objetivo}

O objetivo deste trabalho foi avaliar o uso do CPA como agente coagulante no tratamento de águas de abastecimento com vistas a estudar a sua capacidade de produção de lodo. Pretendeu-se mais especificamente:

- avaliar o comportamento do CPA no que diz respeito à produção de lodo quando empregado de forma isolada ou em conjunto com sais de ferro;

- estudar o impacto do lançamento de lodos gerados em ETAs que empregam CPA como coagulante em ETEs do tipo lodos ativados convencional;

- estudar a composição do lodo final produzido em ETEs que recebam lodos de ETAs gerados a partir do uso do CPA como coagulante em seus sistemas de coleta de esgotos sanitários.

\section{Material e métodos}

A pesquisa foi desenvolvida tendo-se empregado água bruta proveniente do Reservatório do Guarapiranga, um manancial superficial localizado na região metropolitana de São Paulo (RMSP) e que abastece a ETA Alto da Boa Vista (ETA ABV). A ETA ABV é do tipo convencional de ciclo completo, com capacidade de tratamento igual a $15 \mathrm{~m}^{3} / \mathrm{s}$, composta por oito decantadores do tipo convencional de fluxo horizontal e 32 filtros rápidos por gravidade do tipo dupla camada de areia e antracito.

Atualmente, a água de lavagem dos filtros é encaminhada a dois tanques de equalização posteriormente recalcados para o início do processo de tratamento, o que possibilita a sua integral recuperação. Os decantadores, por serem de concepção antiga, são operados em batelada, isto é, após um tempo de operação de 30 dias, são isolados e lavados. Considerando-se que os lodos serão futuramente encaminhados para a ETE Barueri, com vistas a minimizar o impacto do seu lançamento em batelada na rede coletora de esgotos sanitários, o volume do decantador deverá ser enviado a um tanque de equalização de lodos para posterior disposição via rede coletora de esgotos sanitários.

Uma vez que a ETA ABV possui um total de oito decantadores e seu tempo de operação médio é de 30 dias, a cada três dias é efetuado o esgotamento de uma unidade. Dessa forma, a operação do tanque de equalização de lodo deverá considerar a sua operação de enchimento e esvaziamento em um período de três dias, o que irá conferir a regularização da carga de sólidos enviada a ETE Barueri.

As principais características físico-químicas da água bruta empregada nos ensaios experimentais estão apresentadas na Tabela 1. Todas as análises e determinações foram realizadas de acordo com APHA, AWWA, WEF (2005).

Após ser coletada, a água bruta foi acondicionada em bombonas de 20 L de capacidade e imediatamente transportadas ao Laboratório de Saneamento Professor Lucas Nogueira Garcez para a execução dos ensaios experimentais. Os ensaios foram executados em escala de jartest, tendo-se empregado um CPA com basicidade igual a 63\%. A Tabela 2 apresenta as principais características de todos os produtos químicos empregados na investigação experimental.

Os procedimentos adotados na execução dos ensaios de jar-test para fins de quantificação da produção de lodo foram inicialmente a transferência de um volume de 2 L de amostra para cada um dos jarros do equipamento de jar-test. Em seguida, a rotação do sistema de agitação era acertada para cerca de 200 rpm e, imediatamente,

Tabela 1 - Caracterização físico-química da água bruta proveniente do Reservatório do Guarapiranga

\begin{tabular}{|c|c|}
\hline Parâmetros & Reservatório do Guarapiranga \\
\hline $\mathrm{pH}$ & 7,0 a 7,4 \\
\hline Turbidez (UNT) & 3,0 a 6,0 \\
\hline Cor real (UC) & 10 a 15 \\
\hline Cor aparente (UC) & 25 a 60 \\
\hline Condutividade ( $\mu \mathrm{S} / \mathrm{cm})$ & 130 a 140 \\
\hline Alcalinidade (mg CaCO $3 / \mathrm{L})$ & 20 a 35 \\
\hline Fosfato total (mg $\mathrm{PO}_{4}^{-3 / \mathrm{L})}$ & 0,20 a 0,63 \\
\hline Ferro total (mg/L) & 0,1 a 0,5 \\
\hline Manganês total (mg Mn/L) & 0,06 a 0,1 \\
\hline Ferro solúvel (mg/L) & 0,05 a 0,40 \\
\hline Manganês solúvel (mg Mn/L) & 0,04 a 0,08 \\
\hline Sólidos dissolvidos totais (mg/L) & 80 a 90 \\
\hline Sólidos em suspensão totais (mg/L) & 8 a 12 \\
\hline
\end{tabular}


Tabela 2 - Características das soluções empregadas na investigação experimental

\begin{tabular}{lccc} 
Solução & Fórmula & Concentração & Propriedades \\
Hidróxido de sódio & $\mathrm{NaOH}$ & $0,1 \mathrm{M}$ & Solução \\
Sulfato férrico & $\mathrm{Fe}_{2}\left(\mathrm{SO}_{4}\right)_{3}$ & $43 \% \mathrm{como}$ & Solução \\
& $\mathrm{Fe}_{2}\left(\mathrm{SO}_{4}\right)_{3}$ & Densidade: $1.550 \mathrm{~g} / \mathrm{L}$ \\
CPA-63 & Diversas & $11 \% \mathrm{como}$ & Basicidade: $63 \%$ \\
& fórmulas & $\mathrm{Al}_{2} \mathrm{O}_{3}$ & Densidade: $1.000 \mathrm{~g} / \mathrm{L}$ \\
\hline
\end{tabular}

efetuava-se a adição do coagulante (CPA e ou sulfato férrico) e base para a correção do seu pH de coagulação. As dosagens de sulfato férrico e CPA variaram de $0 \mathrm{mg} \mathrm{Fe}{ }_{2}\left(\mathrm{SO}_{4}\right)_{3} / \mathrm{L}$ a $60 \mathrm{mg} \mathrm{Fe}{ }_{2}\left(\mathrm{SO}_{4}\right)_{3} / \mathrm{L}$ e 0 $\mathrm{mg} \mathrm{Al} / \mathrm{L}$ a $15 \mathrm{mg} \mathrm{Al} / \mathrm{L}$, respectivamente.

Os ensaios experimentais contemplaram a avaliação da produção de lodo tendo-se empregado o CPA e o sulfato férrico como coagulante isoladamente e em conjunto. Em caso de aplicação conjunta de ambos os coagulantes, foram contempladas diferentes dosagens de sulfato férrico combinadas a diferentes dosagens de CPA.

A correção do pH de coagulação foi efetuada mediante a adição de volumes pré-determinados de $\mathrm{NaOH} \mathrm{0,1} \mathrm{M} \mathrm{com} \mathrm{base} \mathrm{na} \mathrm{execução}$ de curvas de titulação específicas para cada água bruta em questão. Com a finalidade de possibilitar que ambos os coagulantes operem em regiões de mínima solubilidade, definiu-se que para todos os ensaios de geração de lodo o pH de coagulação seria mantido em torno de 6,0 a 6,5 .

Após 60 segundos de mistura rápida, a rotação era reduzida para $80 \mathrm{rpm}, 50 \mathrm{rpm}$ e $25 \mathrm{rpm}$ e, então, procedia-se à etapa de floculação considerando-se um tempo de mistura lenta de três minutos para as duas primeiras rotações e quatro minutos para a última. Imediatamente após o início da etapa de floculação, efetuava-se a coleta de amostras de água coagulada para fins de determinação da concentração de sólidos em suspensão (SST). Uma vez conhecida a concentração de SST na água bruta, a produção de lodo associada a uma respectiva dosagem de coagulante foi calculada de acordo com a seguinte equação:

$$
P L_{C}=\frac{S S T_{A C}-S S T_{A B}}{D C}
$$

onde:

PLC: produção de lodo associado ao coagulante $\left(\mathrm{MM}^{-1}\right)$; $\mathrm{SST}_{\mathrm{AC}}$ : sólidos em suspensão totais na água coagulada $\left(\mathrm{ML}^{-3}\right)$; $\mathrm{SST}_{\mathrm{AB}}$ : sólidos em suspensão totais na água bruta $\left(\mathrm{ML}^{-3}\right)$; DC: dosagem de coagulante $\left(\mathrm{ML}^{-3}\right)$.

Após dez minutos de floculação, o equipamento era desligado e permitia-se a sedimentação dos flocos previamente formados por cerca de 60 minutos. Em seguida, descartava-se o sobrenadante e efetuava-se a coleta do lodo, de modo que o mesmo pudesse ser empregado nos ensaios posteriores de combinação com lodo digerido proveniente de uma ETE do tipo lodos ativados convencional. Foi escolhida a ETE Barueri operada pela Sabesp e localizada na região metropolitana de São Paulo. A sua vazão afluente atual situa-se em torno de $9,5 \mathrm{~m}^{3} / \mathrm{s}$, em processo de ampliação para $12,5 \mathrm{~m}^{3} / \mathrm{s}$.

Os balanços de massa conduzidos para avaliação dos impactos do emprego do CPA como coagulante e da potencialidade do recebimento de lodos de ETAs em ETEs foram efetuados simulando-se tanto a ETA ABV quanto a ETE Barueri, pois está previsto o futuro lançamento do lodo descarregado pelos decantadores da ETA ABV no sistema de coleta de esgotos sanitários para posterior processamento na ETE Barueri. Os balanços de massa foram efetuados em no programa Microsoft ${ }^{\circledR}$ Excel, tendo-se considerado diferentes cenários de geração de lodo e dosagens de coagulante empregadas na ETA ABV. Para a execução dos balanços de massa da ETE Barueri e ETA ABV, adotaram-se os parâmetros clássicos sugeridos por Metcalf e Eddy (2005) e Montgomery (2005).

Uma vez efetuados e computados os valores de produção de lodo, os ensaios possibilitaram a quantificação do acréscimo de SST no esgoto afluente a ETE Barueri, conforme calculado pela Equação 4.

$C_{a f l}(m g / L)=\left[\frac{M_{E T A}(\mathrm{~kg} / \mathrm{d})+12,5 \mathrm{~m}^{3} / \mathrm{s} .0,3 \mathrm{~kg} / \mathrm{m}^{3} .86 .400 \mathrm{~s} / \text { dia }}{12,5 \mathrm{~m}^{3} / \mathrm{s} .86 .400 \mathrm{~s} / \text { dia }}\right] \cdot 1000 \quad$ Equação 4

onde:

$\mathrm{C}_{\text {afl }}$ : concentração de SST afluente a ETE Barueri $\left(\mathrm{ML}^{-3}\right)$;

$\mathrm{M}_{\mathrm{ETA}}$ : massa de sólidos gerada na ETA ABV e enviada a ETE Barueri $\left(\mathrm{ML}^{-3}\right)$.

O cálculo da concentração de SST afluente a ETE Barueri considerou que a produção de lodo gerada na ETA ABV e descarregada pelos seus decantadores foi equalizada anteriormente ao seu lançamento na rede coletora de esgotos sanitários. A execução do balanço de massa para a ETE Barueri admitiu uma concentração de SST no afluente de 300 mg/L para a sua condição padrão de operação, isto é, sem o encaminhamento do lodo gerado na ETA ABV. A Tabela 3 apresenta um resumo dos balanços de massa efetuados para ambas as ETA ABV e ETE Barueri.

Com base nos resultados dos balanços de massa, foram efetuados ensaios experimentais de combinação de diferentes proporções mássicas de lodo de ETA e lodo digerido da ETE, com vistas a possibilitar o estudo do impacto do lançamento de lodos produzidos a partir do emprego de sais de ferro e CPA como coagulantes no tratamento de águas de abastecimento. Desse modo, foram efetuadas análises da composição dos metais alumínio, ferro, manganês, cobre, cromo e chumbo do lodo gerado durante o processo de tratamento de esgotos na ETE Barueri, para ambos os casos de lançamento e não-lançamento do lodo produzido na ETA ABV na rede coletora de esgotos sanitários.

As amostras de lodo geradas para determinação dos metais foram obtidas a partir de ensaios em laboratório, caracterizadas como tipo úmida. A amostra de lodo gerada na ETE Barueri foi obtida diretamente após a digestão anaeróbia, tendo sido a mesma coletada 
diretamente nos digestores secundários de lodo digerido. Por sua vez, a amostra de lodo de ETA foi gerada em ensaios de jar-test com as respectivas dosagens de sulfato férrico e CPA nas proporções desejadas, como descrito anteriormente.

Os balanços de massa apresentados na Tabela 4 permitiram definir a proporção em que ambos os lodos da ETA e da ETE deveriam ser compostos para simulação de sua composição final. Com base nas informações da carga de SST produzida nos digestores e enviada ao sistema de desidratação (kg/dia) e da massa de sólidos secos gerada pela ETA ABV e disposta no sistema de esgotos sanitários (kg/dia), foi possível calcular a proporção mássica desejada.

Uma vez compostos volumetricamente, esses lodos foram secos em estufa a uma temperatura de $103{ }^{\circ} \mathrm{C}$ durante 24 horas e, após esse período, o resíduo seco foi coletado e acondicionado em frascos de polietileno, sendo enviado posteriormente ao Centro de Química e Meio Ambiente (IPEN-CQMA) para a execução das análises dos metais ferro, alumínio, manganês, cobre, cromo e chumbo pelo método de espectrometria de fluorescência de raios X (WDXRF).

\section{Resultados}

As Figuras 1 e 2 apresentam os valores de produção de sólidos gerados a partir da aplicação unicamente do sulfato férrico e do CPA como coagulante, respectivamente.

A produção de sólidos foi avaliada mediante a determinação da concentração de SST na água coagulada, subtraindo-se o valor de
SST na água bruta. Sendo assim, para diferentes dosagens aplicadas de sulfato férrico, pode-se avaliar a sua produção de lodo inerente à sua aplicação. Com respeito a sais de ferro e alumínio, considerandose a incorporação de águas de hidratação do respectivo hidróxido precipitado, temos:

$\mathrm{Al}^{+3}+3 \mathrm{OH}^{-}+n \mathrm{H}_{2} \mathrm{O} \rightarrow \mathrm{Al}(\mathrm{OH})_{3} \cdot n \mathrm{H}_{2} \mathrm{O} \quad$ Equação 5

$\mathrm{Fe}^{+3}+3 \mathrm{OH}^{-}+n \mathrm{H}_{2} \mathrm{O} \rightarrow \mathrm{Fe}(\mathrm{OH})_{3} \cdot n \mathrm{H}_{2} \mathrm{O} \quad$ Equação 6

Portanto, 1 mol de alumínio e 1 mol de ferro ao precipitarem permitem a formação de também 1 mol de hidróxido férrico ou hidróxido de alumínio associado às suas respectivas águas de hidratação. Geralmente, o valor de n é entre 2 e 4, dependendo do mecanismo de coagulação empregado. Caso ocorra por varredura, o valor de n é mais próximo de 4 , ou menor caso o mecanismo usado seja adsorçãoneutralização ou uma combinação de ambos.

Deste modo, partindo-se das Equações 5 e 6 e assumindo que os valores de $\mathrm{n}$ situem-se entre 2 e 4 , tem-se que para cada $1 \mathrm{mg}$ $\mathrm{Al} / \mathrm{L}$ são formados aproximadamente de 4,22 a 5,56 mg de massa seca de sólidos por litro, ao passo que para cada $1 \mathrm{mg}$ Fe/L são formados de 2,55 a 3,20 mg de massa seca por litro. Com o objetivo de comparar as dosagens tipicamente empregadas no tratamento de águas de abastecimento, tem-se que cada $1 \mathrm{mg} \mathrm{Al} / \mathrm{L}$ corresponde a $11 \mathrm{mg} \mathrm{Al}\left(\mathrm{SO}_{4}\right)_{3} \cdot 14 \mathrm{H}_{2} \mathrm{O} / \mathrm{L}$ e que $1 \mathrm{mg} \mathrm{Fe} / \mathrm{L}$ corresponde a $3,57 \mathrm{mg}$ $\mathrm{Fe}_{2}\left(\mathrm{SO}_{4}\right)_{3} / \mathrm{L}$. Desse modo, para cada $1 \mathrm{mg} \mathrm{Fe}{ }_{2}\left(\mathrm{SO}_{4}\right)_{3} / \mathrm{L}$, espera-se

Tabela 3 - Quadro resumo dos balanços de massa executados para a ETA ABV e ETE Barueri

\begin{tabular}{|c|c|c|c|c|c|c|}
\hline Balanço de massa & $\begin{array}{c}\text { ETA ABV } \\
\text { Vazão }\left(\mathrm{m}^{3} / \mathrm{s}\right)\end{array}$ & $\begin{array}{l}\text { SST da água } \\
\text { bruta (mg/L) }\end{array}$ & $\begin{array}{l}\text { Sulfato férrico } \\
\left(\mathrm{mg} \mathrm{Fe}_{2}\left(\mathrm{SO}_{4}\right)_{3} / \mathrm{L}\right)\end{array}$ & $\mathrm{CPA}(\mathrm{mg} \mathrm{Al} / \mathrm{L})$ & $\begin{array}{l}\text { ETE Barueri } \\
\text { Vazão }\left(\mathrm{m}^{3} / \mathrm{s}\right)\end{array}$ & SST afluente $(\mathrm{mg} / \mathrm{L})$ \\
\hline 1 & 15,0 & 5,0 & 0,0 & 0,0 & 12,5 & 300 \\
\hline 2 & 15,0 & 5,0 & 30,0 & 0,0 & 12,5 & 327 \\
\hline 3 & 15,0 & 5,0 & 22,0 & 0,91 & 12,5 & 326 \\
\hline 4 & 15,0 & 5,0 & 16,0 & 0,91 & 12,5 & 322 \\
\hline 5 & 15,0 & 5,0 & 12,0 & 0,91 & 12,5 & 319 \\
\hline 6 & 15,0 & 5,0 & 8,0 & 0,91 & 12,5 & 317 \\
\hline
\end{tabular}

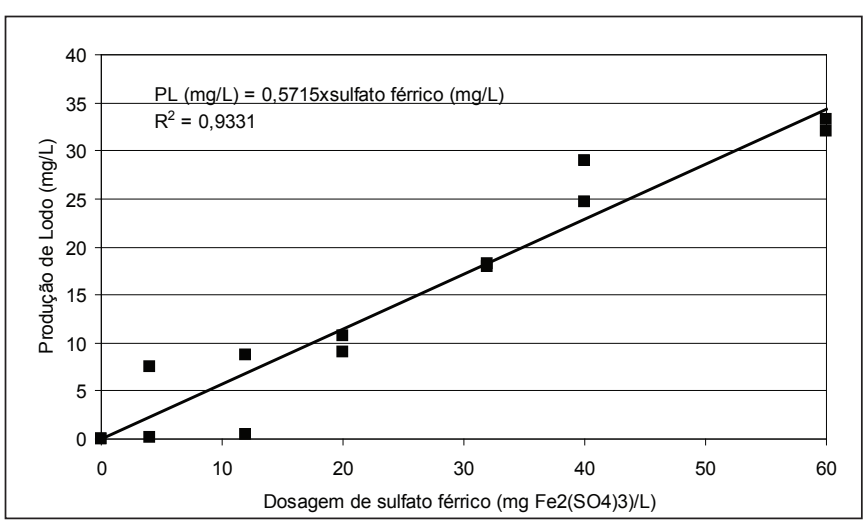

Figura 1 - Avaliação da produção de lodo a partir da aplicação do sulfato férrico como coagulante

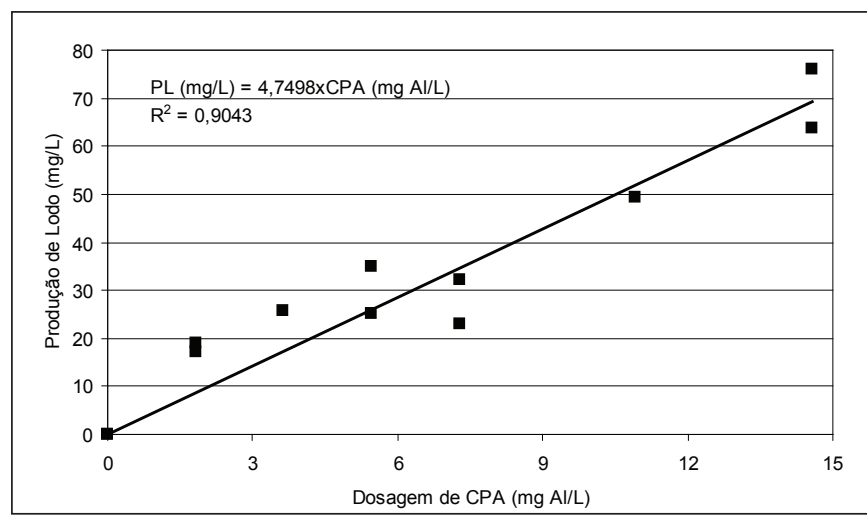

Figura 2 - Avaliação da produção de lodo a partir da aplicação do CPA como coagulante 
a produção de 0,71 a 0,90 mg de massa seca por litro. Portanto, observando-se os resultados experimentais relativos à produção de lodo quando do emprego do sulfato férrico como coagulante, obteve-se uma produção de lodo estimada em 0,57 mg de massa seca por mg de $\mathrm{Fe}_{2}\left(\mathrm{SO}_{4}\right)_{3}$ aplicado por litro, um valor menor em comparação ao esperado. Ainda assim, observa-se uma excelente correlação entre a produção de lodo e a dosagem de sulfato férrico aplicado na fase líquida.

Com respeito ao CPA, obteve-se uma boa correlação entre a produção de lodo e dosagem de CPA, sendo que para cada $1 \mathrm{mg}$ de $\mathrm{Al} / \mathrm{L}$ obteve-se uma produção de lodo de aproximadamente 4,75 mg de massa seca por litro, valor mais próximo do teoricamente esperado. Um aspecto que merece ser observado é que, assumindo dosagens iguais de CPA e sulfato de alumínio expressos como $\mathrm{Al}$, a produção de lodo de ambos é bastante semelhante, e não se pode afirmar que o uso do CPA como coagulante proporcione uma redução na geração de lodo no processo de tratamento.

Dessa forma, considerando o uso do CPA como agente coagulante e assumindo sua constituição preferencial de espécies monoméricas e poliméricas de alumínio, a sua adição na fase líquida tende a proporcionar a polimerização das espécies de alumínio, o que leva à formação do hidróxido metálico, processo semelhante em comparação ao emprego do sulfato de alumínio. Com base nos ensaios de jar-test e tendo-se empregado diferentes dosagens de CPA e sulfato

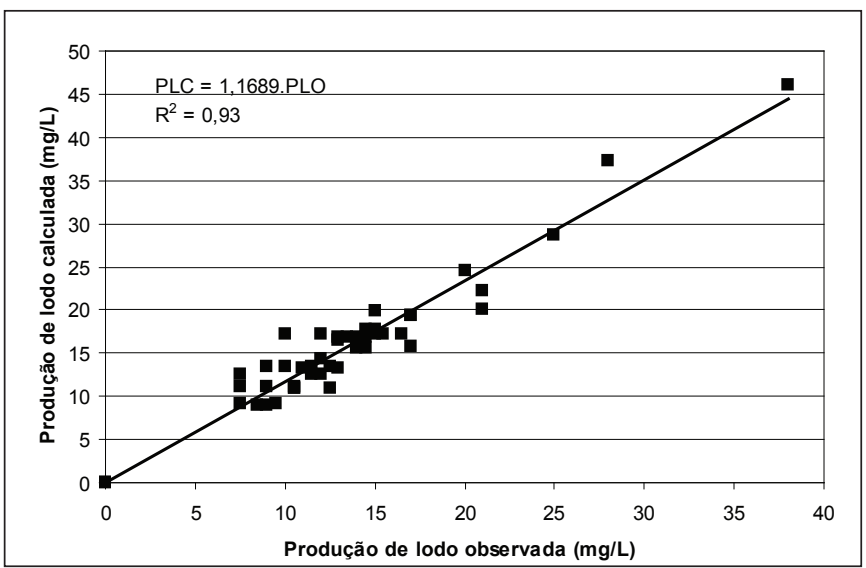

Figura 3 - Avaliação da produção de lodo calculada e observada a partir da aplicação do cloreto de polialumínio e sulfato férrico conjuntamente como coagulantes

Tabela 4 - Resumo dos valores obtidos de produção de lodo para os balanços de massa executados para a ETA ABV

\begin{tabular}{lcccc}
$\begin{array}{l}\text { Balanço } \\
\text { de massa }\end{array}$ & Vazão $\left(\mathrm{m}^{3} / \mathrm{s}\right)$ & $\begin{array}{c}\text { Dosagem de } \\
\text { sulfato férrico } \\
\left(\mathrm{mg} \mathrm{Fe}_{2}\left(\mathrm{SO}_{4}\right)_{3} / \mathrm{L}\right)\end{array}$ & $\begin{array}{c}\text { Dosagem } \\
\text { de CPA } \\
(\mathrm{mg} \mathrm{Al} / \mathrm{L})\end{array}$ & $\begin{array}{c}\text { Produção } \\
\text { de lodo } \\
\text { (ton/dia) }\end{array}$ \\
\hline 1 & 15,0 & 30,0 & 0,0 & 28,70 \\
\hline 3 & 15,0 & 22,0 & 0,91 & 28,38 \\
\hline 4 & 15,0 & 16,0 & 0,91 & 23,93 \\
\hline 5 & 15,0 & 12,0 & 0,91 & 20,97 \\
\hline
\end{tabular}

férrico, para cada um destes calculou-se a produção de lodo teórica em função dos coagulantes empregados a partir dos resultados experimentais apresentados nas Figuras 1 e 2. Portanto, temos:

$P L C=0,5715 \cdot S F+4,7498 \cdot C P A$

Equação 7

onde:

PLC: produção de lodo calculada (mg/L);

SF: dosagem de sulfato férrico como $\mathrm{mg} \mathrm{Fe}_{2}\left(\mathrm{SO}_{4}\right)_{3} / \mathrm{L}$;

CPA: dosagem de cloreto de polialumínio em mg Al/L.

Os valores de produção de lodo calculados foram posteriormente confrontados com os valores observados, estando os seus resultados apresentados na Figura 3

Observando-se a Figura 3 e comparando-se os valores calculados confrontados aos valores experimentais, pode-se notar que a aderência entre eles é muito boa, o que reforça a validade da Equação 7 no cálculo da estimativa da produção de lodo em relação ao uso de ambos os coagulantes, sulfato férrico e CPA. Com base nos valores experimentais obtidos, puderam ser efetuados diferentes cenários de produção de lodo a ser gerada na ETA ABV e posterior disposição na rede coletora de esgotos sanitários para envio à ETE Barueri. A Tabela 4 apresenta um resumo dos valores obtidos de produção de lodo gerada na ETA ABV para os diferentes cenários de dosagem de coagulantes, dispostos na Tabela 3.

Os balanços de massa efetuados para a ETA ABV consideraram dosagens máximas de CPA iguais a 1,0 mg Al/L, pois quando combinadas ao sulfato férrico como coagulante, apresentaram as melhores condições de otimização da qualidade da água decantada (FERREIRA FILHO; WAELKENS, 2007).

Analisando-se os valores de produção de lodo apresentados na Tabela 4, pode-se observar que na condição normal de operação da ETA ABV, isto é, com uma dosagem de coagulante de $30 \mathrm{mg}$ $\mathrm{Fe}_{2}\left(\mathrm{SO}_{4}\right)_{3} / \mathrm{L}$, a sua produção diária é de 28,70 t/dia.

A dosagem de sulfato férrico que permite a mesma produção de lodo quando combinado com uma dosagem de CPA igual a $0,91 \mathrm{mg} \mathrm{Al} / \mathrm{L}$ é da ordem de $22 \mathrm{mg} \mathrm{Fe}_{2}\left(\mathrm{SO}_{4}\right)_{3} / \mathrm{L}$. Portanto, o emprego do CPA como agente coagulante combinado ao sulfato férrico apenas torna-se atrativo em termos de redução na geração de lodo quando a dosagem de sulfato férrico for inferior a $22 \mathrm{mg}$ $\mathrm{Fe}_{2}\left(\mathrm{SO}_{4}\right)_{3} / \mathrm{L}$. Pode-se observar que a aplicação de sulfato férrico com dosagens iguais a 16, 12 e 8 mg $\mathrm{Fe}_{2}\left(\mathrm{SO}_{4}\right)_{3} / \mathrm{L}$ e combinados a uma dosagem de CPA de $0,91 \mathrm{mg} \mathrm{Al/L}$ permitiram uma redução na geração de lodo de $16,6,26,9$ e $37,3 \%$, respectivamente. Desse modo, esses valores foram empregados para a execução do balanço de massa da ETE Barueri, analisando-se o seu incremento nos valores de SST, ferro e alumínio na vazão afluente a ETE, sendo que os valores de SST afluentes a ETE Barueri foram calculados mediante o emprego da Equação 4. 
Assumindo-se que toda a carga de coagulantes aplicada na ETA ABV e expressa como $\mathrm{Fe}^{+3}$ e $\mathrm{Al}^{+3}$ seja convertida a hidróxidos metálicos precipitados e esteja presente no afluente a ETE Barueri, as suas concentrações podem ser calculadas pelas Equações 8 e 9:

$$
\begin{aligned}
& C_{\text {Fe afl }}(m g / L)=\left[\frac{M_{F e}(\mathrm{~kg} / \mathrm{d})}{12,5 \mathrm{~m}^{3} / \mathrm{s} .86 .400 \mathrm{~s} / \mathrm{dia}}\right] \cdot 1000 \\
& C_{\text {Al afl }}(\mathrm{mg} / \mathrm{L})=\left[\frac{\mathrm{M}_{\mathrm{Al}}(\mathrm{kg} / \mathrm{d})}{12,5 \mathrm{~m}^{3} / \mathrm{s} .86 .400 \mathrm{~s} / \mathrm{dia}}\right] \cdot 1000
\end{aligned}
$$

Equação 8

Equação 9

onde:

$\mathrm{C}_{\text {Feafl }}$ : concentração de ferro total afluente a ETE Barueri $\left(\mathrm{ML}^{-3}\right)$;

$\mathrm{C}_{\text {Alafl }}$ : concentração de alumínio total afluente a ETE Barueri $\left(\mathrm{ML}^{-3}\right)$.

A importância de se considerar a carga de Fe e Al no balanço de massa da ETE Barueri se deve ao fato de que, por serem ambos os elementos conservativos e estarem presentes na fase sólida na forma de hidróxidos precipitados, eles tenderão a ser incorporados no lodo desidratado, o que acarretará a alteração das suas características físico-químicas. Assim, com o objetivo de avaliar o impacto da disposição da carga de ferro e alumínio oriundo dos coagulantes empregados na ETA ABV nas características do lodo desidratado, ambos os elementos serão tratados como conservativos e deverão ser integralmente incorporados na fase sólida. A Tabela 5 apresenta um resumo das principais características dos balanços de massa efetuados para a ETE Barueri.

Com o objetivo de permitir uma melhor comparação entre os resultados obtidos com a execução dos balanços de massa para a ETE Barueri, a Tabela 6 apresenta um resumo das principais grandezas calculadas.

A ETE Barueri em suas condições normais de operação, admitindo concentrações de $\mathrm{DBO}_{5,20}$ e SST de 300 mg/L no afluente, deverá produzir uma quantidade de lodo seco em torno de 145 t/dia. Assumindo as atuais condições de operação da ETA ABV, com a utilização somente do sulfato férrico como coagulante com dosagem de $30 \mathrm{mg} \mathrm{Fe}_{2}\left(\mathrm{SO}_{4}\right)_{3} / \mathrm{L}$, o incremento na concentração de SST no afluente a ETE será de $27 \mathrm{mg} / \mathrm{L}$ e, portanto, o seu valor aumentará de 300 $\mathrm{mg} / \mathrm{L}$ para $327 \mathrm{mg} / \mathrm{L}$.

Desse modo, ocorrendo a sua disposição na rede coletora de esgotos sanitários, a produção de lodo na ETE Barueri aumentará de 145 para 171,3 t/dia, o que corresponderá a um aumento de aproximadamente $18,1 \%$. Do mesmo modo, o volume de lodo úmido a ser transportado também deverá aumentar de 456 para $539 \mathrm{~m}^{3} /$ dia. Embora o incremento na concentração, no SST afluente à ETE Barueri, resultante da disposição dos resíduos gerados na ETA ABV por meio do sistema de coleta e afastamento de esgotos sanitários seja relativamente pequeno, de 300 para $327 \mathrm{mg} / \mathrm{L}$, o impacto na produção de lodo seco e volume "úmido" desidratado é significativo, o que deverá proporcionar maiores custos em seu transporte e disposição final.

Como pode ser observado na Tabela 5 , do ponto de vista de diminuição da geração de lodo na ETA ABV mediante o emprego de uma dosagem de CPA igual a 0,91 mg/L, as dosagens de sulfato férrico empregadas no processo de coagulação deverão ser iguais ou menores a $22 \mathrm{mg} \mathrm{Fe}_{2}\left(\mathrm{SO}_{4}\right)_{3} / \mathrm{L}$. Para dosagens de sulfato férrico iguais a 16 e $12 \mathrm{mg} \mathrm{Fe}_{2}\left(\mathrm{SO}_{4}\right)_{3} / \mathrm{L}$, as concentrações de SST no afluente à ETE Barueri deverão ser iguais a 322 e 319 mg/L, respectivamente. Assim, a produção de lodo na respectiva ETE deverá ser de 166,9 e 164,2 t/dia, gerando incrementos de geração de lodo de 15,2 e $13,3 \%$, respectivamente.

Embora tecnicamente possíveis, certas questões devem ser analisadas, mais especificamente com respeito à qualidade do lodo que

Tabela 5 - Resumo dos balanços de massa executados para a ETE Barueri

\begin{tabular}{lccccccc}
$\begin{array}{l}\text { Balanço de } \\
\text { massa }\end{array}$ & Vazão $\left(\mathrm{m}^{3} / \mathbf{s}\right)$ & $\begin{array}{c}\text { Dosagem de } \\
\text { sulfato férrico } \\
\left(\mathrm{mg} \mathrm{Fe}_{2}\left(\mathrm{SO}_{4}\right)_{3} / \mathrm{L}\right)\end{array}$ & $\begin{array}{c}\text { Dosagem de } \\
\mathrm{CPA}(\mathrm{mg} \mathrm{Al} / \mathrm{L})\end{array}$ & $\begin{array}{c}\text { Lodo oriundo da } \\
\mathrm{ETA} \mathrm{ABV} \mathrm{(t/dia)}\end{array}$ & $\begin{array}{c}\mathrm{SST} \text { afluente } \\
(\mathrm{mg} / \mathrm{L})\end{array}$ & $\mathrm{Fe}(\mathrm{mg} / \mathrm{L})$ & $\mathrm{Al}(\mathrm{mg} / \mathrm{L})$ \\
\hline 1 & 12,5 & 0,0 & 0,0 & 0,0 & 300 & 0,0 & 0,0 \\
\hline 2 & 12,5 & 30,0 & 0,0 & 28,70 & 327 & 10,08 & 0,0 \\
\hline 3 & 12,5 & 22,0 & 0,91 & 28,38 & 326 & 7,39 & 1,09 \\
\hline 4 & 12,5 & 16,0 & 0,91 & 23,93 & 322 & 5,38 & 1,09 \\
\hline 5 & 12,5 & 12,0 & 0,91 & 20,97 & 319 & 4,03 & 1,09 \\
\hline 6 & 12,5 & 8,0 & 0,91 & 18,01 & 317 & 2,69 & 1,09 \\
\hline
\end{tabular}

\begin{tabular}{|c|c|c|c|c|c|c|}
\hline Balanço de massa & Vazão $\left(\mathrm{m}^{3} / \mathrm{s}\right)$ & $\begin{array}{l}\text { Dosagem de } \\
\text { sulfato férrico (mg } \\
\left.\mathrm{Fe}_{2}\left(\mathrm{SO}_{4}\right)_{3} / \mathrm{L}\right)\end{array}$ & $\begin{array}{c}\text { Dosagem de CPA } \\
\text { (mg Al/L) }\end{array}$ & $\begin{array}{l}\text { Lodo oriundo da } \\
\text { ETA ABV (t/dia) }\end{array}$ & $\begin{array}{c}\text { Produção de lodo } \\
\text { (t/dia) }\end{array}$ & $\begin{array}{l}\text { Volume de lodo } \\
\text { "úmido" ( } \mathrm{m}^{3} / \mathrm{dia} \text { ) }\end{array}$ \\
\hline 1 & 12,5 & 0,0 & 0,0 & 0,0 & 144,9 & 455,9 \\
\hline 2 & 12,5 & 30,0 & 0,0 & 28,70 & 171,3 & 538,5 \\
\hline 3 & 12,5 & 22,0 & 0,91 & 28,38 & 170,9 & 537,6 \\
\hline 4 & 12,5 & 16,0 & 0,91 & 23,93 & 166,9 & 524,8 \\
\hline 5 & 12,5 & 12,0 & 0,91 & 20,97 & 164,2 & 516,3 \\
\hline 6 & 12,5 & 8,0 & 0,91 & 18,01 & 161,5 & 507,8 \\
\hline
\end{tabular}

Tabela 6 - Resumo dos resultados obtidos para os balanços de massa executados para a ETE Barueri com respeito à produção de lodo 
deverá ser gerado na ETE Barueri. Com base nos resultados obtidos por meio do balanço de massa para a ETE Barueri, assumiu-se que a carga de Fe e Al empregados como coagulantes na ETA ABV deveriam estar na forma de hidróxidos metálicos precipitados na forma sólida $e$, consequentemente, seriam incorporados posteriormente ao lodo desidratado. A Tabela 7 apresenta os valores de concentração de Fe e Al esperados para o lodo desidratado, bem como seus valores de relação SSVISST para o lodo desidratado.

Observando-se a Tabela 7, pode-se notar que, com a disposição do lodo da ETA ABV na ETE Barueri, as concentrações de Fe e Al no lodo desidratado deverão ser bastante elevadas, o que deverá impor restrições no que diz respeito à sua disposição final, tipicamente o uso agrícola. Os valores de concentração de ambos os metais no lodo desidratado podem ser confrontados com os valores calculados a partir da execução do balanço de massa da ETE Barueri, apresentados nas Figuras 4 e 5 .

Com base na Figura 4, verifica-se que há uma similaridade de comportamento entre as concentrações de Fe calculadas por meio do balanço de massa da ETE Barueri e as observadas após a composição de ambos os lodos de ETA e ETE. Embora as concentrações calculadas tenham sido ligeiramente maiores do que as observadas, a sua tendência a aumentar em função das maiores dosagens aplicadas de sulfato férrico como coagulante na ETA ABV ficou muito bem caracterizada.

Assim, como já explicitado anteriormente, a eventual disposição dos lodos gerados em ETAs em rede coletora de esgotos sanitários para posterior processamento em ETEs tenderá a ocasionar uma modificação na qualidade do lodo desidratado, restringindo o seu uso posterior. Em caso de disposição em aterros sanitários, essa mudança em sua composição físico-química não deverá ser um problema significativo.

A Figura 5 apresenta o valor de concentração de $\mathrm{Al}$ observado e calculado por intermédio do balanço de massa para os lodos compostos. De acordo com os resultados experimentais, pode-se notar que o seu acréscimo foi bastante reduzido, e não significativo. Isso se justifica pelo fato de a máxima concentração aplicada de CPA como coagulante não ter sido superior a 1,0 mg Al/L. As Figuras 6 e 7 apresentam as concentrações de cobre $(\mathrm{Cu})$, cromo $(\mathrm{Cr})$, manganês $(\mathrm{Mn})$ e chumbo $(\mathrm{Pb})$ observadas para os lodos gerados mediante a composição do lodo da ETA ABV e ETE Barueri.

Observando-se as Figuras 6 e 7, pode-se notar que para os metais $\mathrm{Cu}, \mathrm{Cr}$ e Pb, não foram observadas alterações nas concentrações no lodo composto em função da adição de lodo de ETA gerado sob diferentes concentrações de agentes coagulantes. Desse modo, independentemente das condições em que foram gerados os lodos da ETA, as concentrações de $\mathrm{Cu}$, Cr e Pb situaram-se em torno de 800, 600 e 100 mg/kg, respectivamente, o que justifica a sua origem mediante sua incorporação à fase sólida por processos de remoção físico-química quando presentes no esgoto bruto. Uma vez que a ETE Barueri localiza-se em uma região com elevada intensidade industrial, justifica-se a sua presença no esgoto bruto por serem oriundos da implantação de um programa de recebimento de efluentes não-domésticos na rede coletora de esgotos sanitários.

Tabela 7 - Resumo dos resultados obtidos para os balanços de massa executados para a ETE Barueri com respeito à qualidade do lodo desidratado

\begin{tabular}{|c|c|c|c|c|c|c|}
\hline Balanço de massa & Vazão $\left(\mathrm{m}^{3} / \mathrm{s}\right)$ & $\begin{array}{l}\text { Dosagem de sulfato } \\
\text { férrico }\left(\mathrm{mg} \mathrm{Fe}_{2}\left(\mathrm{SO}_{4}\right)_{3} / \mathrm{L}\right)\end{array}$ & Dosagem de CPA (mg Al/L) & $\begin{array}{l}\text { Lodo oriundo da } \\
\text { ETA ABV (ton/dia) }\end{array}$ & $\mathrm{Fe}(\mathrm{g} / \mathrm{kg})$ & $\mathrm{Al}(\mathrm{g} / \mathrm{kg})$ \\
\hline 1 & 12,5 & 0,0 & 0,0 & 0,0 & 0,0 & 0,0 \\
\hline 2 & 12,5 & 30,0 & 0,0 & 28,70 & 63,6 & 0,0 \\
\hline 3 & 12,5 & 22,0 & 0,91 & 28,38 & 46,7 & 6,89 \\
\hline 4 & 12,5 & 16,0 & 0,91 & 23,93 & 34,8 & 7,07 \\
\hline 5 & 12,5 & 12,0 & 0,91 & 20,97 & 26,5 & 7,18 \\
\hline 6 & 12,5 & 8,0 & 0,91 & 18,01 & 17,9 & 7,30 \\
\hline
\end{tabular}

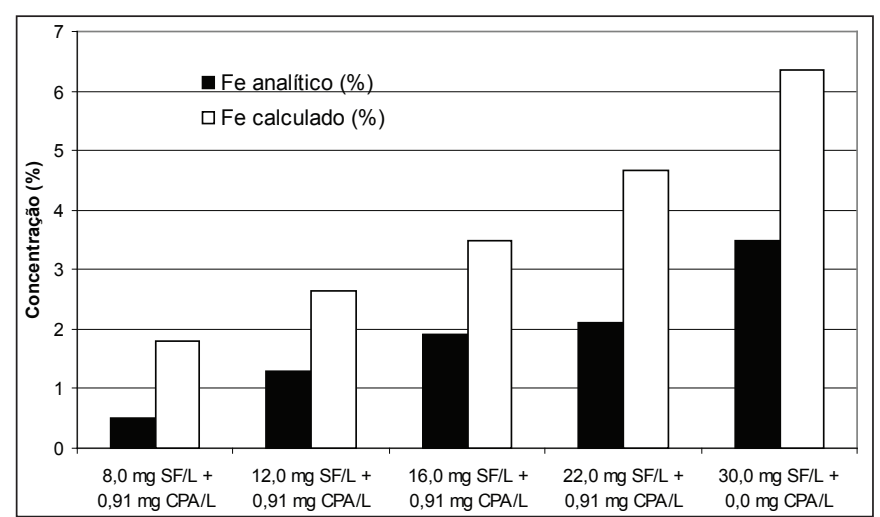

Figura 4 - Concentrações de Fe observadas e calculadas para o lodo digerido da ETE Barueri combinado com o lodo da ETA ABV

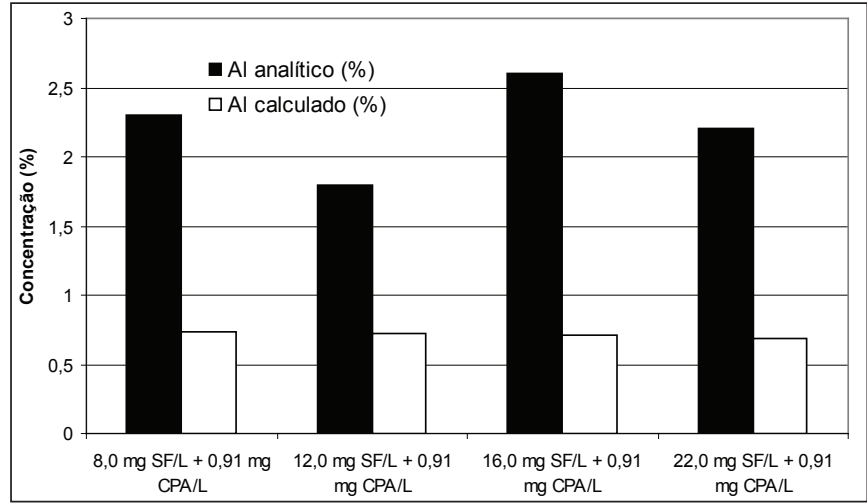

Figura 5 - Concentrações de Al observadas e calculadas para o lodo digerido da ETE Barueri combinado com o lodo da ETA ABV 


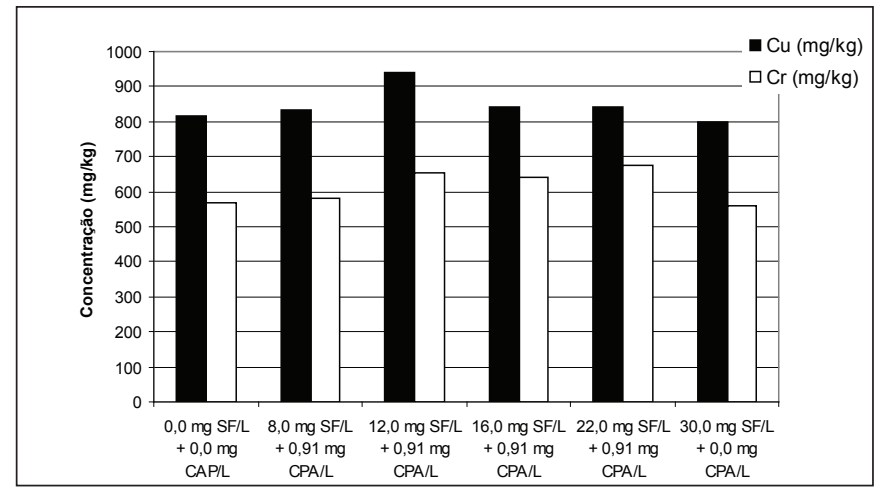

Figura 6 - Concentrações de Cu e Cr observadas para o lodo digerido da ETE Barueri combinado com o lodo da ETA ABV

O único elemento que apresentou comportamento diferenciado foi o manganês, sendo que, com a introdução do lodo gerado na ETA $\mathrm{ABV}$ e respectivo aumento da dosagem de sulfato férrico, observou-se um nítido aumento na sua concentração no lodo composto, de 280 $\mathrm{mg} / \mathrm{kg}$ para quase $1.000 \mathrm{mg} / \mathrm{kg}$. A razão pela qual ocorreu esse incremento está, portanto, associada à sua presença no coagulante, pois quanto maiores as dosagens aplicadas na ETA, maiores tenderão a ser as concentrações de Mn introduzido na água coagulada e, em função de sua precipitação na forma de dióxido de manganês, também maiores serão as suas concentrações incorporadas na fase sólida.

Desse modo, a composição físico-química do lodo a ser desidratado na ETE Barueri não será função unicamente do lançamento de efluentes industriais e dos metais base oriunda do coagulante (alumínio ou ferro), mas também de suas impurezas que deverão ser incorporadas na fase sólida. Uma vez conhecida a origem e a concentração dos elementos que podem alterar potencialmente a composição físico-química dos lodos da ETE por meio de execução de balanços de massa, podem-se efetuar previsões acerca do impacto na qualidade do lodo desidratado e suas implicações com respeito à sua disposição final.

\section{Conclusões}

Com base nos resultados experimentais, pode-se concluir que:

- a produção de lodo oriunda da aplicação do sulfato férrico como coagulante esteve em torno de 0,57 mg de massa seca para cada

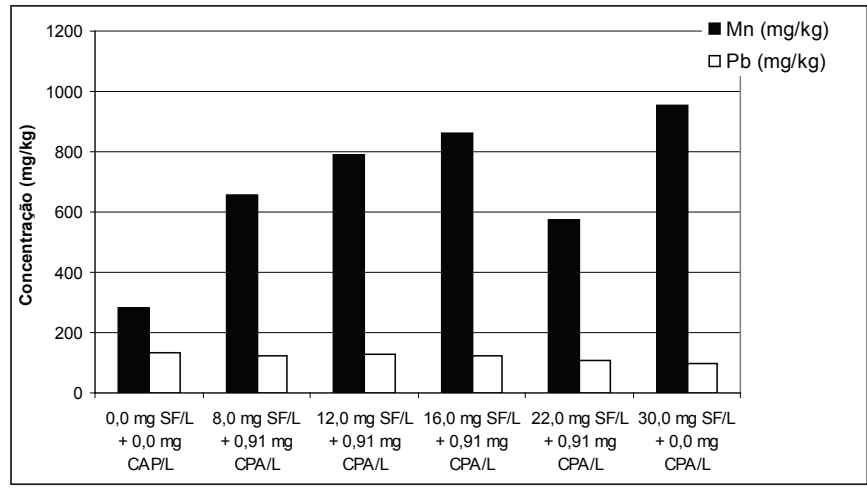

Figura 7 - Concentrações de $\mathrm{Mn}$ e $\mathrm{Pb}$ observadas para o lodo digerido da ETE Barueri combinado com o lodo da ETA ABV

mg de $\mathrm{Fe}_{2}\left(\mathrm{SO}_{4}\right)_{3}$, sendo ligeiramente inferior ao valor teórico esperado, de 0,71 mg/mg;

- com respeito ao CPA, obtiveram-se valores de produção de lodo de 4,75 mg de massa seca para cada $1 \mathrm{mg}$ de Al, resultado mais próximo do valor teórico de 4,22 mg/mg;

- observou-se que a produção de lodo do CPA apresentou valores próximos quando comparado ao sulfato de alumínio e, dessa forma, é possível afirmar que ambos os coagulantes apresentam comportamento semelhante com respeito à produção de lodo;

- quando possível a disposição de lodos de ETAs via rede coletora de esgotos sanitários para posterior processamento em ETEs, espera-se que a qualidade do lodo desidratado sofra significativas alterações em sua qualidade físico-química, com função do tipo e dosagem de coagulante, bem como de suas principais impurezas, notadamente, metais pesados;

- a eventual disposição dos lodos da ETA ABV para posterior processamento na ETE Barueri deverá elevar as concentrações de Fe e Al no lodo desidratado, esperando-se que situem-se em torno de 64 e $7 \mathrm{~g} / \mathrm{kg}$, respectivamente.

\section{Agradecimentos}

À Fundação de Amparo à Pesquisa do Estado de São Paulo (Fapesp) pelo apoio financeiro concedido (processo 2004/03178-6) e bolsa de iniciação científica (processo 2004/03177-0).

\section{Referências}

APHA/AWWA/WEF. Standard Methods for the Examination of Water and Wastewater. 21. ed. Washington, DC: APHA/AWWA/WEF, 2005.

AMERICAN SOCIETY OF CIVIL ENGINEERS. Management of water treatment plant residuals. New York: ASCE, 1996.
AMERICAN WATER WORKS ASSOCIATION. POlymeric inorganic coagulants. Denver: AWWA, 1989.

Water treatment plant waste management. Denver: AWWA, 
BARBOSA, A.B.D.; MENDES, M.J.; BAYLÃO, T.W.S. Emprego do policloreto de alumínio em uma estação de filtração direta com água proveniente de manancial em processo de eutrofização. In: $22^{\circ}$ CONGRESSO BRASILEIRO DE ENGENHARIA SANITÁRIA E AMBIENTAL, 1., Anais... Joinville, 2003.

DALSASSO, R.L.; SENS, M.L. Filtração direta com pré-Floculação e coagulação com sulfato de alumínio e hidroxicloreto de alumínio: estudo com água de manancial eutrofizado. Revista Engenharia Sanitária e Ambiental, v. 11, n. 3, p. 241-249, 2006.

FERREIRA FILHO, S.S.; WAELKENS, B.E. Aspectos químicos do cloreto de polialumínio como coagulante no tratamento de águas de abastecimento. Submetido a publicação à Revista Engenharia Sanitária e Ambiental, 2007. (no prelo).

FERREIRA FILHO, S.S. et al Aplicação de polímeros catiônicos em conjunto com coagulantes inorgânicos como auxiliares de coagulação para a otimização de estações de tratamento de água. In: 22 CONGRESSO BRASILEIRO DE ENGENHARIA SANITÁRIA E AMBIENTAL, 1., Anais... Joinville, 2003.
JANUÁRIO, G.F.; FERREIRA FILHO, S.S. Planejamento e aspectos ambientais envolvidos na disposição final de lodos das estações de tratamento de água da região metropolitana de São Paulo. Revista Engenharia Sanitária e Ambiental, v. 12, n. 2, p. 117-126, abr./jun. 2007.

METCALF \& EDDY, INC. Wastewater engineering: treatment, disposal, reuse. 4. ed. Australia: McGraw-Hill, 2005. Metcalf \& Eddy, Inc

MONTGOMERY, J. Water treatment: principles and design. 2. ed. New York: John Wiley \& Sons, 2005.

PERNITSKY, D.J.; EDZWALD, J.K. Solubility of polyaluminium coagulants. Journal of Water Supply: Research and Technology, v. 52, n. 3, p. 395406, 2003.

ROTH, D.K. et al Implementing residuals management: costs implication for coagulation and softening plants. Journal American Water Works Association, v. 100, n. 3, p. 81-93, mar. 2008 